\title{
Disease burden and treatment challenges of psoriatic arthritis in Africa and the Middle East
}

\author{
Mohamed Bedaiwi ${ }^{1} \cdot$ Ibrahim A. Al-Homood $^{2} \cdot$ Ayman El-Garf $^{3}(-) \cdot$ Imad Uthman $^{4}\left({ }^{\circ} \cdot\right.$ Nancy Sunna $^{5}(D)$ \\ Reenad Nassier ${ }^{6} \cdot$ Haytham Mohamed $^{6}$ (1) $\cdot$ Jamal Al Saleh $^{7}$
}

Received: 8 February 2019 / Accepted: 3 May 2019 / Published online: 27 May 2019

(c) The Author(s) 2019

\begin{abstract}
Psoriatic arthritis (PsA) is a chronic, inflammatory arthropathy occurring in up to $30 \%$ of patients with psoriasis, and is characterized by multiple manifestations including peripheral arthritis, enthesitis, dactylitis, spondylitis, and psoriatic skin and nail disease. This complex and heterogeneous disease is poorly understood and its diagnosis and treatment are suboptimal, particularly in Africa and the Middle East, where very few studies into the impact of PsA have been carried out. This article aims to highlight the disease burden of PsA in the region as well as to identify unmet clinical needs. A non-systematic review was carried out in the PubMed database and the most relevant publications were selected. Expert rheumatologists practicing in Africa and the Middle East provide an insight into the challenges of treating PsA in daily practice, along with recommendations for improvements.
\end{abstract}

Keywords Africa $\cdot$ Disease burden $\cdot$ Middle East $\cdot$ Prevalence $\cdot$ Psoriatic arthritis $\cdot$ Spondyloarthritis

\section{Introduction}

Psoriatic arthritis (PsA) is a member of the spondyloarthritis family of diseases and affects approximately $30 \%$ of patients with psoriasis [1]. This chronic immune-mediated inflammatory disease is characterized by multiple manifestations including peripheral arthritis, enthesitis, dactylitis, spondylitis, and psoriatic skin and nail disease [1,2], which may

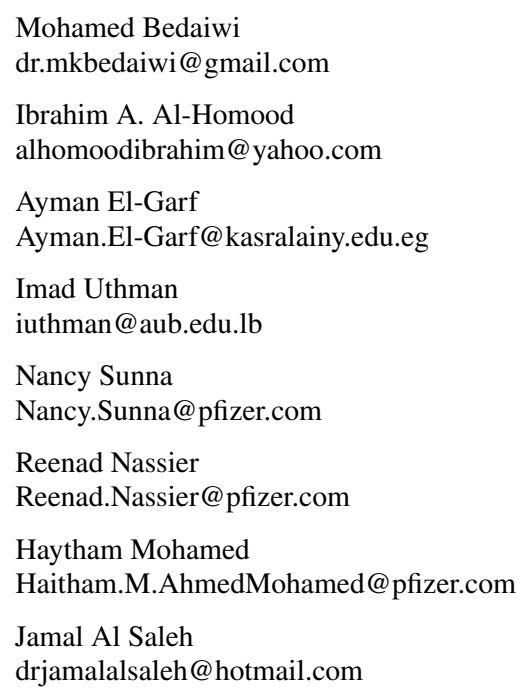

occur alone or in combination [3]. Since PsA is a clinically diverse and heterogeneous disease, both in presentation and severity [4], management is particularly challenging and requires an interdisciplinary approach [5]. Recent advances in the understanding of the immunological mechanisms underlying PsA are providing new insights into the pathogenesis of the disease [6], enabling the development of targeted therapies that can improve patient outcomes [7].

Division of Rheumatology, College of Medicine, King Saud University Medical City, King Saud University, Riyadh, Saudi Arabia

2 Department of Medical Specialties, Rheumatology Section, King Fahad Medical City, Riyadh, Saudi Arabia

3 Rheumatology Department, Cairo University Hospitals, Cairo University, Cairo, Egypt

4 Division of Rheumatology, American University of Beirut Medical Center, Beirut, Lebanon

5 Pfizer Inc, Amman, Jordan

6 Pfizer Inc, Jeddah, Saudi Arabia

7 Rheumatology Unit, Dubai Hospital, Dubai Health Authority, Dubai, United Arab Emirates 
However, there is still much to learn and both the diagnosis and treatment of PsA remain suboptimal [7]. This is particularly true for the large and diverse region of Africa and the Middle East, where very few studies into PsA have been carried out, and consequently the extent of the disease burden is poorly understood and improvements in the management and treatment of PsA are much needed [5].

The objective of this review is to highlight the disease burden of PsA in Africa and the Middle East and to identify unmet clinical needs and the physical and psychosocial impact of PsA in the region.

\section{Literature search strategy}

Non-systematic literature searches were conducted using PubMed (https://www.ncbi.nlm.nih.gov/pubmed), incorporating all studies published on or before March 01, 2019 (10 year limit) based on the following search terms: (Africa OR sub-Saharan Africa OR Algeria OR Bahrain OR Egypt OR Iran OR Iraq OR Jordan OR Kuwait OR Lebanon OR Libya OR Middle East OR Morocco OR Oman OR Qatar OR Saudi Arabia OR South Africa OR Syria OR Tunisia OR United Arab Emirates OR Yemen) AND psoriatic arthritis
AND prevalence OR burden. A search replacing 'psoriatic arthritis' with 'spondyloarthritis' was also performed. A search of African Journals Online (https://www.ajol.info) was also conducted based on the following search terms: psoriatic arthritis OR spondyloarthritis. Additionally, the African Journal of Rheumatology, published African League Against Rheumatism (AFLAR) Congress abstracts (2013), and recent Asia Pacific League of Associations for Rheumatology (APLAR) Congress abstracts (2015-2018) were reviewed for relevant studies. The literature search results were manually reviewed for relevance, and articles reporting PsA in countries outside of Africa and the Middle East were excluded. References in all relevant articles were examined to identify other articles of interest and, in addition to the searches, the authors drew on their knowledge of the wider literature to provide context. Figure 1 shows a flowchart of the non-systematic literature selection process and the 12 articles initially identified from the literature search are detailed in Table 1.

The authors, who are expert rheumatologists practicing in Africa and the Middle East, also provide an insight into the challenges of treating PsA in daily practice from personal experience, along with recommendations for improvements.

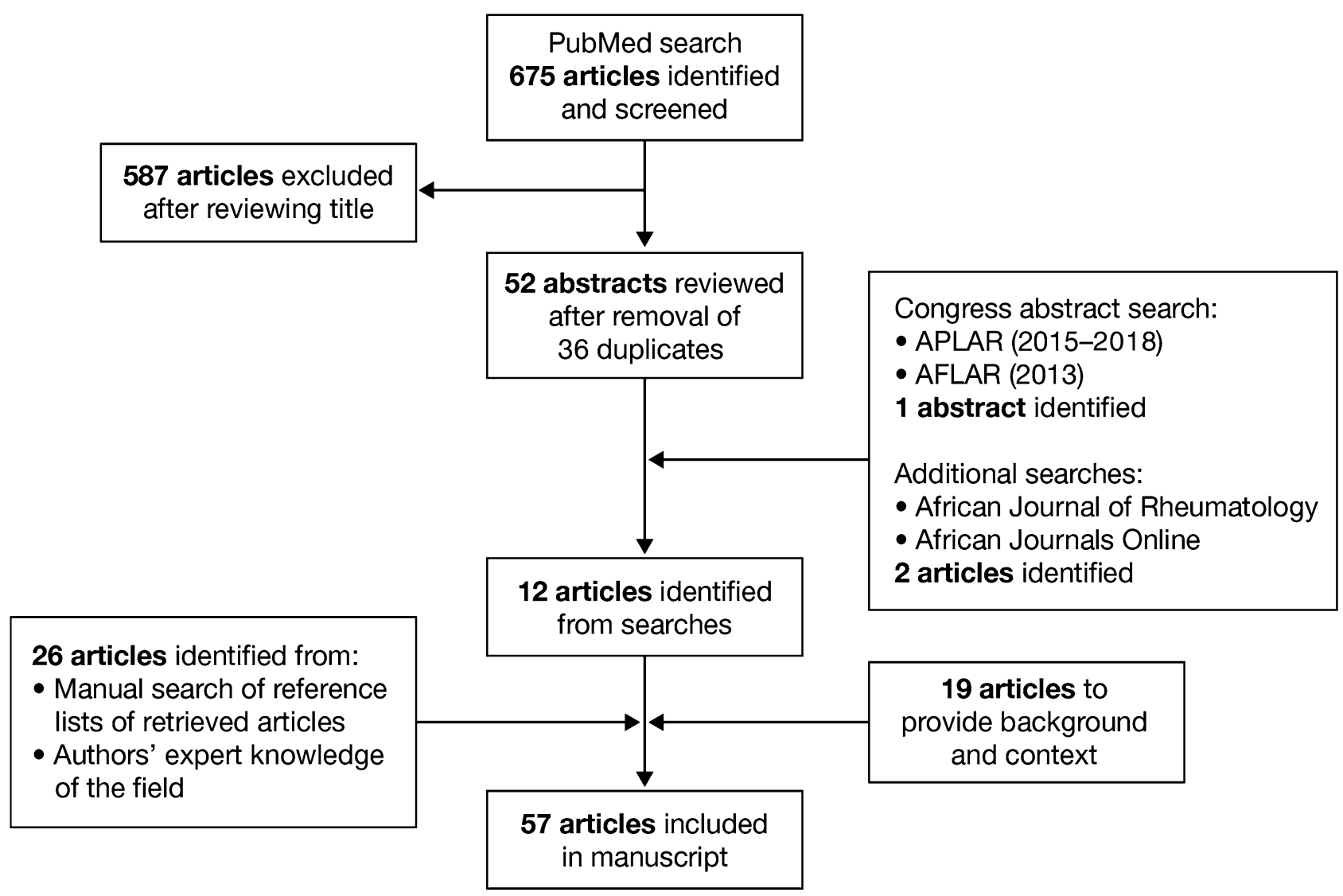

Fig. 1 Flowchart of the non-systematic literature selection process 
Table 1 Articles identified in the literature search

\begin{tabular}{|c|c|c|}
\hline Article & Type & Main observations \\
\hline Abdulghani et al. [5] & $\begin{array}{l}\text { Review and expert opinion of dermatologists in Africa and } \\
\text { the Middle East }\end{array}$ & $\begin{array}{l}\text { The management of psoriasis and PsA is suboptimal in } \\
\text { Africa and the Middle East }\end{array}$ \\
\hline Al Hammadi et al. [8] & $\begin{array}{l}\text { Survey of expert dermatologists in Africa and the Middle } \\
\text { East }\end{array}$ & $\begin{array}{l}\text { There was a lack of consensus in the use of biologics for the } \\
\text { treatment of psoriasis and PsA in clinical practice, which } \\
\text { was attributed to low physician awareness, high cost, and } \\
\text { non-adherence }\end{array}$ \\
\hline Conaghan et al. [9] & $\begin{array}{l}\text { Multi-national survey of dermatologists and rheumatolo- } \\
\text { gists in the Asia-Pacific region and the Middle East }\end{array}$ & $\begin{array}{l}\text { Patients waited an average of } 0.9 \text { years for a confirmed } \\
\text { diagnosis of PsA, and longer for appropriate treatment } \\
(n=364)\end{array}$ \\
\hline Elnady et al. [10] & $\begin{array}{l}\text { Study of patients with psoriasis from two tertiary medical } \\
\text { centers in Saudi Arabia }\end{array}$ & $\begin{array}{l}\text { During a 2-year clinical follow-up of patients with psoriasis, } \\
\text { the annual incidence of PsA was reported to be } 4.3 \% \\
(n=104)\end{array}$ \\
\hline Harmse et al. [11] & Review of bDMARD use in South Africa & $\begin{array}{l}\text { The prohibitive cost of biologics limits their use in resource- } \\
\text { poor countries }\end{array}$ \\
\hline Jamshidi et al. [12] & Single-center cross-sectional study of PsA in Tehran, Iran & PsA was reported in $29 / 320$ patients with psoriasis $(9.1 \%)$ \\
\hline Lebughe et al. [13] & $\begin{array}{l}\text { Prospective hospital-based study in the Democratic } \\
\text { Republic of Congo }\end{array}$ & $\begin{array}{l}\text { One case of PsA reported among } 984 \text { patients }(0.1 \%) \text { attend- } \\
\text { ing two rheumatology practices }\end{array}$ \\
\hline Maharaj et al. [14] & Single-center study of PsA in South Africa & $\begin{array}{l}\text { A study of } 384 \text { patients with PsA reported the complete } \\
\text { absence of black South African patients with PsA }\end{array}$ \\
\hline Mgonda et al. [15] & A cross-sectional hospital-based study in Tanzania & $\begin{array}{l}\text { Two cases of PsA among } 42 \text { patients with psoriasis }(5 \%) \\
\text { attending specialized skin clinics in Tanzania }\end{array}$ \\
\hline Ouédraogo et al. [16] & Review article of PsA in sub-Saharan Africa & $\begin{array}{l}\text { No data available on the prevalence of PsA in sub-Saharan } \\
\text { Africa }\end{array}$ \\
\hline Stolwijk et al. [17] & $\begin{array}{l}\text { Systematic review and meta-regression analysis of the } \\
\text { global prevalence of spondyloarthritis }\end{array}$ & $\begin{array}{l}\text { There is large variation in the reported global prevalence of } \\
\text { PsA } \\
\text { Prevalence of PsA in the Middle East and North Africa was } \\
\text { reported as } 0.01 \% \text { ( } 95 \% \text { CI } 0.00-0.17 \% \text { ) }\end{array}$ \\
\hline Usenbo et al. [18] & $\begin{array}{l}\text { Systematic review and meta-analysis of the prevalence of } \\
\text { arthritis in Africa }\end{array}$ & $\begin{array}{l}\text { There is a lack of reliable data on the prevalence and burden } \\
\text { of PsA in Africa }\end{array}$ \\
\hline
\end{tabular}

bDMARD biologic disease-modifying antirheumatic drug, $P s A$ psoriatic arthritis

\section{Incidence and prevalence of PsA in Africa and the Middle East}

There is considerable variation in the reported global incidence and prevalence of PsA [17, 19]. The global annual incidence of PsA has been reported as ranging from 0.1 to 23.1 cases per 100,000 (median 6.4) in the general population [19], while global prevalence rates of PsA are estimated to range from 0.001 to $0.42 \%$, depending on geographic region $[17,19,20]$.

There are several factors causing this wide variation in global estimates, including the use of different methodologies used to identify cases of PsA. Those studies with the lowest prevalence estimates have used International Classification of Disease (ICD-9) codes or clinical classification criteria, while those with higher estimates have utilized self-reported diagnosis techniques [20-23]. Another factor that may partially explain the wide differences in the global prevalence is the variable expression of the HLA-B27 allele, which is a genetic biomarker of PsA-populations with a high frequency of this gene are reported to have higher rates of PsA [24]. Additionally, patients with PsA expressing this allele tend to develop musculoskeletal symptoms faster, are more prone to developing enthesitis, dactylitis, and uveitis, and develop an axial disease pattern with more bone marrow edema in sacroiliac joints [24].

The HLA-B27 allele is widespread in the population throughout Europe and Asia, and very highly prevalent in the native populations of arctic and subarctic regions such as Alaska and Greenland, but is effectively absent in the native population of other regions, such as South America, Australia, and parts of Equatorial and Southern Africa [25].

Population-based studies have estimated the prevalence of PsA in the United States to be $0.25 \%$ [95\% confidence interval (CI) $0.18-0.31 \%$ ] [20] and in the United Kingdom to be $0.19 \%$ (95\% CI 0.185-0.193\%) [26]. However, a comparison with African and Middle Eastern populations is not currently possible since the majority of research into PsA has been carried out in Western countries and there are very few published studies on the prevalence and burden of PsA in Africa and the Middle East [5, 18], which was evident in our literature search. Consequently, the reported global estimates of incidence and 
prevalence may not be reflective of this very large and diverse region [5]. Indeed, the lack of local registries, reliable diagnosis, and reporting of PsA has led to the impression that it is relatively rare in Africa and the Middle East, when in fact the burden of the disease is unknown [16]; a similar observation has been reported for rheumatoid arthritis (RA) [27].

In a recent systematic review and meta-regression analysis, the prevalence of PsA in the Middle East and North Africa was reported to be $0.01 \%$ (95\% CI $0.00-0.17 \%$ ) [17]. However, this estimate was based on a single population study from Kuwait, in which one case of PsA was identified in a survey of 7670 adults [28]. A cross-sectional population-based study of 3985 patients attending primary healthcare clinics in the United Arab Emirates estimated the prevalence of PsA to be $0.3 \%$ [29], while an Iranian single-center cross-sectional study of 320 patients with psoriasis reported that $9.1 \%$ had PsA [12]. A population-based study of $>3000$ adults in Lebanon used the Community Oriented Program for the Control of Rheumatic Diseases (COPCORD) methodology, which estimated the prevalence of spondyloarthropathies to be $0.3 \%$; however, the survey did not specifically identify any cases of PsA [30]. During a 2-year clinical follow-up of patients with psoriasis from two tertiary medical centers in Saudi Arabia, the annual incidence of PsA was reported to be 4.3\% $(n=104)$ [10]. This was the only study identified in our search that reported annual incidence rates in Africa and the Middle East.

The prevalence of PsA in the general population of subSaharan Africa is unknown, but it has been reported sporadically in isolated studies [16]. Hospital-based studies have reported the prevalence of PsA to be $1 \%$ (95\% CI -0.10 to 2.10) in patients with HIV in urban Uganda $(n=300), 0.01 \%$ (95\% CI -0.01 to 0.02 ) among 12,494 outpatients in a rheumatology clinic in urban Cameroon [18, 31, 32], and 0.1\% (one occurrence) of 984 patients attending two rheumatology practices in the Democratic Republic of Congo [13]. A cross-sectional hospital-based study reported two cases of PsA among 42 patients with psoriasis (5\%) attending specialized skin clinics in Tanzania [15]. A single-center study of 384 patients in South Africa reported no black South African patients with PsA, rather all patients attending the clinic were mixed race, or of Indian or European descent. The authors suggested that this lack of susceptibility could be due to yet-to-be-identified protective genes in this population [14]. This inconsistent and sporadic reporting highlights the need for more epidemiological studies of PsA in Africa and the Middle East.

\section{Diagnosis and management of PsA in Africa and the Middle East}

Prior to the introduction of the criteria developed by the ClASsification of Psoriatic ARthritis (CASPAR) study group [33], the lack of universally accepted diagnostic and classification criteria for PsA hindered the understanding of the burden of PsA [34].

Guidelines published by the European League Against Rheumatism (EULAR) and the American College of Rheumatology (ACR)/National Psoriasis Foundation (NPF) provide recommendations for the management of PsA [35, 36]. A limitation of the EULAR guidelines is that they are focused on the management of the musculoskeletal manifestations of PsA, while the management of psoriatic skin disease is not addressed [37]. Clinical guidelines for PsA jointly developed by ACR/NPF were recently published and are the first to include new therapeutic agents for the treatment of PsA, such as inhibitors of interleukin (IL)-17 and Janus kinase. These guidelines provide treatment recommendations for the management of both musculoskeletal disease and severe psoriasis [36].

Recommendations published by the Group for Research and Assessment of Psoriasis and Psoriatic Arthritis (GRAPPA) are preferred by some clinicians as they encompass key PsA disease domains (i.e., arthritis, spondylitis, enthesitis, dactylitis, skin disease, and nail disease), and these recommendations are frequently implemented in the Africa and Middle East region [2]. According to GRAPPA, the ultimate goals of therapy for patients with PsA are (1) to achieve the lowest possible level of disease activity in all domains of disease, (2) to optimize functional status, improve quality of life and wellbeing, and prevent structural damage to the greatest extent possible, and (3) to avoid or minimize complications, both from untreated active disease and from therapy. They recommend that all major disease domains of PsA are considered, including examining the impact of the disease on pain, function, quality of life, and structural damage. GRAPPA recommends that clinical assessments should include patient-reported outcome measures, a comprehensive medical history, and physical examination, along with laboratory tests and imaging techniques [2].

GRAPPA recommendations may be more applicable for use in Africa and the Middle East, a diverse and large area that includes both resource-poor and resource-rich countries, because it provides 'standard' and 'expedited' therapeutic recommendations for each clinical domain; the standard treatment for axial disease would begin with nonsteroidal anti-inflammatory drugs and progress to biologic disease-modifying antirheumatic drugs (bDMARDs; e.g., tumor necrosis factor, IL-17, or IL-12/23 inhibitors) in inadequate responders, while the expedited option would initiate treatment with bDMARDs directly [2]. Hence, GRAPPA's 'standard' arm could be the initial treatment option for the resource-poor countries, while GRAPPA's 'expedited' treatment recommendations may be most appropriate in resource-rich countries. 
The International League of Associations for Rheumatology (ILAR) group supports projects that advance rheumatology in countries where there is an exceptional need [38]. As current treatment guidelines may not be directly applicable in resource-poor countries, such as those in Central/ South America and Africa, ILAR has recently adapted the GRAPPA and EULAR guidelines for this purpose. These adapted recommendations are mainly based on GRAPPA, with some EULAR recommendations, and have incorporated input from local regional experts [39]. While these adapted recommendations may not be useful throughout the whole of Africa and the Middle East, they are a step toward developing regional guidelines. The lack of consistency when applying treatment guidelines for PsA management in Africa and the Middle East likely means that different practices are being implemented within individual countries, and between physicians within the same hospitals.

\section{Physical and psychosocial disease impact of PsA in Africa and the Middle East}

The physical and psychosocial disability associated with PsA places a substantial burden on patients due to its diverse clinical spectrum. In addition to debilitating joint damage, the presence of psoriatic skin disease can cause patients embarrassment, self-consciousness, and depression [40]. The substantial burden of PsA on patient quality of life has been reported in studies carried out in North America and Europe [41]. However, further research is required in Africa and the Middle East as we were unable to identify any studies specifically addressing the physical and psychosocial disease impact of PsA in the region. A population-based study highlighted the substantial burden of musculoskeletal pain and rheumatic disorders in Lebanon, reporting that $6.4 \%$ (95\% CI $4.2-8.5 \%)$ of patients had functional disability and $26.0 \%$ (95\% CI 22.3-30.1\%) required treatment $(n=500)$; however, the authors noted that research in this area and recognition by health authorities in the region is seriously lacking [42, 43].

Sleep disturbance is a common symptom of PsA [40, 44] and while there are no specific studies investigating its impact in Africa and the Middle East, a cross-sectional study of Moroccan patients with ankylosing spondylitis reported that inflammatory pain and depression are risk factors for sleep problems $(n=110)$ [45], a finding that could potentially be extrapolated to PsA. There is a requirement for clinical studies to be conducted in Africa and the Middle East to assess the impact of PsA on sleep disturbance.

PsA has been described as a systemic disease because, alongside the inflammatory skin and joint manifestations, comorbidities are common and are associated with a reduced quality of life. It is estimated that around $40 \%$ of patients with PsA have three or more comorbidities, which may include cardiovascular disease, metabolic syndrome, obesity, diabetes, fatty liver disease, depression, and anxiety [46, 47].

\section{Unmet needs in the management of PsA in Africa and the Middle East}

As there are very limited data available on the prevalence and incidence of PsA in Africa and the Middle East, there is a need to develop registries across this region to monitor patients with PsA and gather real-world data on the extent and impact of the disease.

In sub-Saharan Africa, a shortage of qualified health professionals is a contributory factor to the lack of rheumatology services, and there is an urgent need to improve rheumatology training and services [48]. Initiatives such as the International League Against Rheumatism (ILAR)East Africa Initiative and East, Central and Southern Africa College of Physicians (ECSACoP) aim to enhance medical training in this region through collaboration with the international rheumatology community, and these partnerships are vital for the development of rheumatology care in subSaharan Africa [49-51].

There is also a need for specific guidelines to be developed for the management of PsA in Africa and the Middle East, as the current published guidelines are primarily focused on the United States and Europe. Two recent editorials detail multiple obstacles faced by rheumatologists practicing in Africa and the Middle East, including a lack of disease awareness among both patients and healthcare professionals, drug accessibility, inadequate health funding, and a lack of rheumatologists [27, 52]. While these obstacles are applicable to the management of PsA, treatment is further complicated by the requirement for both a rheumatologist and a dermatologist to provide care to patients and by the presence of multiple clinical domains, each of which may require a different therapy [2].

Delays in the referral of patients with PsA to rheumatologists is a challenge in Africa and the Middle East which, similarly to RA, is likely to be a result of multiple patientrelated and physician-related factors [53]. One such factor may be primary care practitioners and dermatologists not recognizing the symptoms of PsA due to a lack of training in identifying the disease. This is a serious concern for rheumatologists, because when patients are eventually evaluated, they are often already suffering from advanced arthritis and joint deformity [54]. The results of a multi-national survey carried out in the Middle East found that patients waited an average of 0.9 years for a confirmed diagnosis of PsA, and longer for appropriate treatment $(n=364)$ [9]. This highlights the urgent need for consistent and reliable diagnostic criteria to be implemented in the region.

The role of specialist nurses is to help patients understand their treatment, assist clinicians, and aid communication 
between the multidisciplinary team [55], which in addition to rheumatologists and dermatologists may include a physiotherapist, a dietician, a psychologist, and a social worker. However, access to such resources is not widespread in Africa and the Middle East and is dependent on the healthcare service available in each country [52]. The logistics of running a multidisciplinary clinic within an outpatient clinic setting and the limited availability of interested dermatologists, specialist nurses, and clinic coordinators are limiting factors (author opinion).

While all medications licensed for the treatment of PsA are available in some African and Middle Eastern countries, their prohibitive cost limits their use in resource-poor countries [11]. There is also considerable variability in patient accessibility to treatment, since, even in clinics where all treatments and services are available and funded, the actions of individual patients and the route that they take to gain access to services remain an important factor (author opinion). In the absence of studies on the diagnosis of PsA in the region, we can draw parallels with studies carried out on the diagnosis of RA. For example, a study carried out in the United Arab Emirates found that patients with early RA were referred to a rheumatologist faster by a secondary specialist than by a general practitioner [56], and a recent observational study performed in Saudi Arabia identified that early referral to a rheumatologist was an important factor in the timely diagnosis and treatment of RA [57]. Therefore, establishing early referral criteria that can support primary care physicians and dermatologists to identify the signs of PsA is required to provide earlier and better care.

A further challenge in the management of PsA in Africa and the Middle East is the lack of patient understanding of their disease, which affects their adherence to medication. Rheumatologists find that patients are not aware of available treatment options, which may be due to a shortage of patient education programs and nursing staff. Many patients suffering from PsA are seen by dermatologists only and are never referred to a rheumatologist because they are more concerned about their skin disease and have not sought help for other symptoms (author opinion).

In addition to the considerable differences in health services between countries in Africa and the Middle East, there also exists significant healthcare system complexities and variability within the same country; in the United Arab Emirates for example, there are three different government healthcare providers in addition to the private health sector. In Egypt, there is limited funding for most of the state and university hospitals, whereas a small number of military and police hospitals are better resourced. While affluent patients can access the benefits of the private health sector, this is unaffordable for the majority of patients in the region, who rely on government hospitals (including university hospitals and clinics), which cannot fund expensive treatments. As would be expected, there is a wide variation between the standard of medical services provided by the private hospitals and the government or university hospitals, which is reflected in the options made available to patients. Patients with health insurance can be treated with bDMARDs if they meet the eligibility criteria, yet many patients in this region do not have either insurance coverage or government support. These patients cannot easily access the services that they require, such as radiological investigations or treatment with bDMARDs, resulting in patients with undertreated PsA (author opinion).

Sickness compensation is not available in all regions; in the United Arab Emirates, there is a federal committee for medical fitness that grants light duties and early retirement based on a patient's disability that is refractory to recommended treatment. In Lebanon, sickness compensation is dependent on the employer, with only those few patients working in certain industries, such as banks, receiving this benefit (author opinion).

Healthcare budget restraints, insurance restrictions, low incomes, and the absence of sickness compensation schemes all limit access to new therapies. Also, some clinicians experience difficulties in convincing insurance companies to consider new biologic therapies if they are in the same class as an existing therapy. However, it should be noted that insurance companies have a lower threshold for approving biologics for PsA than for psoriasis (author opinion). A recent survey of expert dermatologists in the region reported a lack of consensus in the use of biologics for the treatment of psoriasis in clinical practice, which was attributed to low physician awareness, high cost, and non-adherence [8]. The main sources of funding for PsA treatment in the region are insurance coverage, charities, supportive programs from pharmaceutical companies, and government support (author opinion).

\section{Recommendations for improvement in PsA treatment and management in Africa and the Middle East}

Based on our first-hand experience of the healthcare system and the challenges of treating and managing patients with PsA in Africa and the Middle East, we propose the following personal recommendations for improvement:

1. The development of specific guidelines for the management of PsA in Africa and the Middle East. These guidelines should consider the health resources in each country and also take into account different socio-economic situations, which vary widely in the region.

2. The introduction of specialized multidisciplinary clinics involving both a rheumatologist and a dermatologist to aid the early diagnosis of PsA. 
(a) Improve early diagnosis through increased screening of patients with psoriasis. Ensuring that all patients receive effective treatment for PsA immediately following diagnosis will positively improve patient outcomes. Ideally, patients should be reviewed promptly, offered regular evaluation by appropriate specialists, and have treatment adjusted as needed in order to achieve the goals of therapy.

(b) The introduction of a screening questionnaire for PsA in dermatology clinics. This may help to identify patients that have symptoms of rheumatic disease and facilitate early referral to a rheumatologist. Some rheumatologists and dermatologists in the region have agreed to use the Early ARthritis for Psoriatic patients' (EARP) questionnaire, or the Psoriasis Epidemiology Screening Tool (PEST), which is available via the GRAPPA smart phone application. Other rheumatologists already implement a low threshold for accepting referrals of patients with PsA, agreeing that a patient presenting with psoriasis and joint pain ( \pm lower back pain) should be assessed, and this should also be implemented by dermatologists.

3. A patient education and awareness program in the form of a collaboration between patients and medical societies to enhance both patient and primary physicians' education. This could be implemented by providing patients with leaflets and reading materials to understand more about PsA and treatment management. The introduction of early referral educational programs for primary care and general practitioners and educating pharmacists, nurses, and regulatory authorities on PsA disease burden and the impact on patient quality of life may be beneficial.

4. Improved access to biologics and other new therapies to treat PsA. To allow more patients access to new therapies, more rheumatology clinics are required, along with wider insurance coverage, and increased cooperation between the government and private sectors.

\section{Conclusions}

PsA is poorly understood and under-recognized in Africa and the Middle East due to a paucity of quality research, which was evident in our literature search. This review represents a further step towards unveiling the burden of PsA in Africa and the Middle East, and proposes recommendations for improvements in PsA treatment and management in the region. This includes the requirement to establish regional PsA guidelines to define the standard-of-care required, introducing specialized multidisciplinary clinics to aid early diagnosis and appropriate treatment management, encouraging patient and physician education of PsA, and increased cooperation between governments and private sectors to improve access to new therapies. Furthermore, the burden of PsA should be listed on the research agenda of African and Middle Eastern countries to provide much needed data that can be used in the future to obtain health funders' support for this chronic disease.

Acknowledgements The authors would like to thank Professors Bassel El Zorkany and Fouad Fayad for their valuable input in developing the concept of the manuscript. Medical writing support, under the guidance of the authors, was provided by Jennifer Higginson, $\mathrm{PhD}$, at $\mathrm{CMC}$ Connect, a division of McCann Health Medical Communications Ltd, Glasgow, UK, and was funded by Pfizer Inc, New York, NY, USA in accordance with Good Publication Practice (GPP3) guidelines (Ann Intern Med 2015;163:461-464).

Author contributions All authors were involved in designing the concept of the review and critically evaluated and revised the manuscript. All authors read and approved the final manuscript.

Funding This study was sponsored by Pfizer Inc.

\section{Compliance with ethical standards}

Conflicts of interest M Bedaiwi-received speaker fees from AbbVie and Pfizer Inc. I Al Homood-received speaker's fees and advisory board honoraria from AbbVie, Lilly, Novartis and Pfizer Inc. A ElGarf-received speaker's fees and advisory board honoraria from AbbVie, Janssen, Novartis, Pfizer Inc, Roche and UCB. I Uthman-received speaker fees from AbbVie, Janssen, Newbridge, and Pfizer Inc. J Al Saleh-received research grant from AbbVie and Pfizer Inc. N Sunna, R Nassier, and H Mohamed-employees and shareholders of Pfizer Inc.

Data availability statement Data sharing not applicable to this article as no datasets were generated or analyzed during the current study.

Open Access This article is distributed under the terms of the Creative Commons Attribution 4.0 International License (http://creativeco mmons.org/licenses/by/4.0/), which permits unrestricted use, distribution, and reproduction in any medium, provided you give appropriate credit to the original author(s) and the source, provide a link to the Creative Commons license, and indicate if changes were made.

\section{References}

1. Ritchlin CT, Colbert RA, Gladman DD (2017) Psoriatic arthritis. N Engl J Med 376:957-970. https://doi.org/10.1056/NEJMra1505 557

2. Coates LC, Kavanaugh A, Mease PJ, Soriano ER, Laura AcostaFelquer M, Armstrong AW, Bautista-Molano W, Boehncke WH, Campbell W, Cauli A, Espinoza LR, FitzGerald O, Gladman DD, Gottlieb A, Helliwell PS, Husni ME, Love TJ, Lubrano E, McHugh N, Nash P, Ogdie A, Orbai AM, Parkinson A, O'Sullivan D, Rosen CF, Schwartzman S, Siegel EL, Toloza S, Tuong W, 
Ritchlin CT (2016) Group for Research and Assessment of Psoriasis and Psoriatic Arthritis 2015 treatment recommendations for psoriatic arthritis. Arthritis Rheumatol 68:1060-1071. https://doi. org/10.1002/art.39573

3. Liu JT, Yeh HM, Liu SY, Chen KT (2014) Psoriatic arthritis: epidemiology, diagnosis, and treatment. World J Orthop 5:537-543. https://doi.org/10.5312/wjo.v5.i4.537

4. Ritchlin CT, Kavanaugh A, Gladman DD, Mease PJ, Helliwell P, Boehncke WH, de Vlam K, Fiorentino D, Fitzgerald O, Gottlieb AB, McHugh NJ, Nash P, Qureshi AA, Soriano ER, Taylor WJ (2009) Treatment recommendations for psoriatic arthritis. Ann Rheum Dis 68:1387-1394. https://doi.org/10.1136/ ard.2008.094946

5. Abdulghani M, Al Sheik A, Alkhawajah M, Ammoury A, Behrens F, Benchikhi H, Benkaidali I, Doss N, El Gendy A, Mokhtar I, Odendaal D, Raboobee N, Thaçi D, Weiss R, Whitaker D (2011) Management of psoriasis in Africa and the Middle East: a review of current opinion, practice and opportunities for improvement. J Int Med Res 39:1573-1588. https://doi. org/10.1177/147323001103900501

6. Kang EJ, Kavanaugh A (2015) Psoriatic arthritis: latest treatments and their place in therapy. Ther Adv Chronic Dis 6:194203. https://doi.org/10.1177/2040622315582354

7. Tucker LJ, Ye W, Coates LC (2018) Novel concepts in psoriatic arthritis management: can we treat to target? Curr Rheumatol Rep 20:71. https://doi.org/10.1007/s11926-018-0781-x

8. Al Hammadi A, Al-Sheikh A, Ammoury A, Ghosn S, Gisondi P, Hamadah I, Kibbi AG, Shirazy K (2017) Experience and challenges for biologic use in the treatment of moderate-tosevere psoriasis in Africa and the Middle East region. J Dermatolog Treat 28:129-135. https://doi.org/10.1080/09546 634.2016.1183763

9. Conaghan PG, Strand V, Deodhar A, Sullivan E, Blackburn S, Tian H, Gandhi K, Jug1 SM, Alten R (2017) ABS273 Appropriate psoriatic arthritis (PSA) treatment is delayed for years: multinational survey results including Asia Pacific (APAC) and Middle East (ME). Int J Rheumatic Dis 20(Suppl 1):66

10. Elnady B, El Shaarawy NK, Dawoud NM, Elkhouly T, Desouky DE, ElShafey EN, El Husseiny MS, Rasker JJ (2019) Subclinical synovitis and enthesitis in psoriasis patients and controls by ultrasonography in Saudi Arabia; incidence of psoriatic arthritis during two years. Clin Rheumatol. https://doi.org/10.1007/s1006 7-019-04445-0

11. Harmse L, Reuter H (2016) An overview of the biological disease modifying drugs available for arthritic conditions in South Africa. S Afr Fam Pract 58:6-10

12. Jamshidi F, Bouzari N, Seirafi H, Farnaghi F, Firooz A (2008) The prevalence of psoriatic arthritis in psoriatic patients in Tehran, Iran. Arch Iran Med 11:162-165. https://doi.org/10.08112/ AIM.008

13. Lebughe P, de Vlam K, Westhovens R, Mbuyi-Muamba JM, Malemba JJ (2018) Spondyloarthritis in the Democratic Republic of the Congo: a prospective hospital-based study. BMJ Open 8:e020329. https://doi.org/10.1136/bmjopen-2017-020329

14. Maharaj AB, Rajkaran M, Govender J, Maharaj K, De Vries N, Tak PP (2016) Psoriatic arthritis: an assessment of clinical, biochemical and radiological features in a single-centre South African cohort. S Afr Med J. https://doi.org/10.7196/SAMJ.2016. v106i6.10347

15. Mgonda YM (2007) Psoriatic - arthritis among psoriasis patients attending skin clinics n Dar es Salaam, Tanzania. Tanzania Med J 22:40-42. https://doi.org/10.4314/tmj.v22i1.39219

16. Ouédraogo DD, Meyer O (2012) Psoriatic arthritis in Sub-Saharan Africa. Joint Bone Spine 79:17-19. https://doi.org/10.1016/j.jbspi n.2011.06.007
17. Stolwijk C, van Onna M, Boonen A, van Tubergen A (2016) Global prevalence of spondyloarthritis: a systematic review and meta-regression analysis. Arthritis Care Res (Hoboken) 68:1320 1331. https://doi.org/10.1002/acr.22831

18. Usenbo A, Kramer V, Young T, Musekiwa A (2015) Prevalence of arthritis in Africa: a systematic review and meta-analysis. PLoS One 10:e0133858. https://doi.org/10.1371/journal.pone.0133858

19. Alamanos Y, Voulgari PV, Drosos AA (2008) Incidence and prevalence of psoriatic arthritis: a systematic review. J Rheumatol 35:1354-1358

20. Gelfand JM, Gladman DD, Mease PJ, Smith N, Margolis DJ, Nijsten T, Stern RS, Feldman SR, Rolstad T (2005) Epidemiology of psoriatic arthritis in the population of the United States. J Am Acad Dermatol 53:573. https://doi.org/10.1016/j.jaad.2005.03.046

21. Asgari MM, Wu JJ, Gelfand JM, Salman C, Curtis JR, Harrold LR, Herrinton LJ (2013) Validity of diagnostic codes and prevalence of psoriasis and psoriatic arthritis in a managed care population, 1996-2009. Pharmacoepidemiol Drug Saf 22:842-849. https ://doi.org/10.1002/pds.3447

22. Shbeeb M, Uramoto KM, Gibson LE, O'Fallon WM, Gabriel SE (2000) The epidemiology of psoriatic arthritis in Olmsted County, Minnesota, USA, 1982-1991. J Rheumatol 27:1247-1250

23. Löfvendahl S, Theander E, Svensson A, Carlsson KS, Englund M, Petersson IF (2014) Validity of diagnostic codes and prevalence of physician-diagnosed psoriasis and psoriatic arthritis in southern Sweden-a population-based register study. PLoS One 9:e98024. https://doi.org/10.1371/journal.pone.0098024

24. Queiro R, Morante I, Cabezas I, Acasuso B (2016) HLA-B27 and psoriatic disease: a modern view of an old relationship. Rheumatology (Oxford) 55:221-229. https://doi.org/10.1093/rheumatolo gy/kev296

25. Gabriel SE, Michaud K (2009) Epidemiological studies in incidence, prevalence, mortality, and comorbidity of the rheumatic diseases. Arthritis Res Ther 11:229. https://doi.org/10.1186/ar266 9

26. Ogdie A, Langan S, Love T, Haynes K, Shin D, Seminara N, Mehta NN, Troxel A, Choi H, Gelfand JM (2013) Prevalence and treatment patterns of psoriatic arthritis in the UK. Rheumatology (Oxford, England) 52:568-575. https://doi.org/10.1093/rheum atology/kes324

27. El Zorkany B, Alwahshi HA, Hammoudeh M, Al Emadi S, Benitha R, Al Awadhi A, Bouajina E, Laatar A, El Badawy S, Al Badi M, Al-Maini M, Al Saleh J, Alswailem R, Ally MM, Batha W, Djoudi H, El Garf A, El Hadidi K, El Marzouqi M, Hadidi M, Maharaj AB, Masri AF, Mofti A, Nahar I, Pettipher CA, Spargo CE, Emery P (2013) Suboptimal management of rheumatoid arthritis in the Middle East and Africa: could the EULAR recommendations be the start of a solution? Clin Rheumatol 32:151159. https://doi.org/10.1007/s10067-012-2153-7

28. Al-Awadhi AM, Olusi SO, Moussa M, Shehab D, Al-Zaid N, AlHerz A, Al-Jarallah K (2004) Musculoskeletal pain, disability and health-seeking behavior in adult Kuwaitis using a validated Arabic version of the WHO-ILAR COPCORD Core Questionnaire. Clin Exp Rheumatol 22:177-183

29. Al Saleh J, Sayed ME, Monsef N, Darwish E (2016) The prevalence and the determinants of musculoskeletal diseases in Emiratis attending primary health care clinics in Dubai. Oman Med J 31:117-123. https://doi.org/10.5001/omj.2016.23

30. Chaaya M, Slim ZN, Habib RR, Arayssi T, Dana R, Hamdan O, Assi M, Issa Z, Uthman I (2012) High burden of rheumatic diseases in Lebanon: a COPCORD study. Int J Rheum Dis 15:136143. https://doi.org/10.1111/j.1756-185X.2011.01682.x

31. Singwe-Ngandeu M, Meli J, Ntsiba H, Nouédoui C, Yollo AV, Sida MB, Muna WF (2007) Rheumatic diseases in patients attending a clinic at a referral hospital in Yaounde, Cameroon. East Afr Med J 84:404-409 
32. Kaddu-Mukasa M, Ssekasanvu E, Ddumba E, Thomas D, Katabira ET (2011) Rheumatic manifestations among HIV positive adults attending the Infectious Disease Clinic at Mulago Hospital. Afr Health Sci 11:24-29

33. Taylor W, Gladman D, Helliwell P, Marchesoni A, Mease P, Mielants H (2006) Classification criteria for psoriatic arthritis: development of new criteria from a large international study. Arthritis Rheum 54:2665-2673. https://doi.org/10.1002/art.21972

34. Congi L, Roussou E (2010) Clinical application of the CASPAR criteria for psoriatic arthritis compared to other existing criteria. Clin Exp Rheumatol 28:304-310

35. Gossec L, Smolen JS, Ramiro S, de Wit M, Cutolo M, Dougados M, Emery P, Landewé R, Oliver S, Aletaha D, Betteridge $\mathrm{N}$, Braun J, Burmester G, Cañete JD, Damjanov N, Fitzgerald O, Haglund E, Helliwell P, Kvien TK, Lories R, Luger T, Maccarone M, Marzo-Ortega H, McGonagle D, McInnes IB, Olivieri I, Pavelka K, Schett G, Sieper J, van den Bosch F, Veale DJ, Wollenhaupt J, Zink A, van der Heijde D (2016) European League Against Rheumatism (EULAR) recommendations for the management of psoriatic arthritis with pharmacological therapies: 2015 update. Ann Rheum Dis 75:499-510. https://doi.org/10.1136/ annrheumdis-2015-208337

36. Singh JA, Guyatt G, Ogdie A, Gladman DD, Deal C, Deodhar A, Dubreuil M, Dunham J, Husni ME, Kenny S, Kwan-Morley J, Lin J, Marchetta P, Mease PJ, Merola JF, Miner J, Ritchlin CT, Siaton B, Smith BJ, Van Voorhees AS, Jonsson AH, Shah AA, Sullivan N, Turgunbaev M, Coates LC, Gottlieb A, Magrey M, Nowell WB, Orbai AM, Reddy SM, Scher JU, Siegel E, Siegel M, Walsh JA, Turner AS, Reston J (2018) 2018 American College of Rheumatology/National Psoriasis Foundation Guideline for the Treatment of Psoriatic Arthritis. Arthritis Care Res (Hoboken). https://doi.org/10.1002/acr.23789

37. Coates LC, Gossec L, Ramiro S, Mease P, van der Heijde D, Smolen JS, Ritchlin C, Kavanaugh A (2017) New GRAPPA and EULAR recommendations for the management of psoriatic arthritis. Rheumatology (Oxford) 56:1251-1253. https://doi. org/10.1093/rheumatology/kew390

38. International League of Associations for Rheumatology (ILAR). http://www.ilar.org/. Accessed 14 Mar 2019

39. Elmamoun M, Eraso M, Maharaj AB, Chandran V, Coates L (2018) OP0312 International league of associations for rheumatology (ILAR) treatment recommendations for psoriatic arthritis in resource-poor countries. Ann Rheum Dis 77(Suppl 2):203. https ://doi.org/10.1136/annrheumdis-2018-eular.5536

40. Husni ME, Merola JF, Davin S (2017) The psychosocial burden of psoriatic arthritis. Semin Arthritis Rheum 47:351-360. https ://doi.org/10.1016/j.semarthrit.2017.05.010

41. Lee S, Mendelsohn A, Sarnes E (2010) The burden of psoriatic arthritis: a literature review from a global health systems perspective. P T 35:680-689

42. Slim ZN, Chaaya M, Habib RR, Arayssi T, Uthman I (2011) High burden of musculoskeletal conditions: a problem that has only recently come to recognition. Chronic Illn 7:311-320. https://doi. org/10.1177/1742395311420611

43. Slim ZF, Uthman I (2012) The state of rheumatic diseases in Lebanon. A call for research and education. Rheumatology (Oxford) 51:1929-1930. https://doi.org/10.1093/rheumatology/kes208

44. Gezer O, Batmaz İ, Sariyildiz MA, Sula B, Ucmak D, Bozkurt M, Nas K (2017) Sleep quality in patients with psoriatic arthritis. Int J Rheum Dis 20:1212-1218. https://doi. org/10.1111/1756-185X.12505

45. Hakkou J, Rostom S, Mengat M, Aissaoui N, Bahiri R, HajjajHassouni N (2013) Sleep disturbance in Moroccan patients with ankylosing spondylitis: prevalence and relationships with diseasespecific variables, psychological status and quality of life. Rheumatol Int 33:285-290. https://doi.org/10.1007/s00296-012-2376-6

46. Ogdie A, Schwartzman S, Husni ME (2015) Recognizing and managing comorbidities in psoriatic arthritis. Curr Opin Rheumatol 27:118-126. https://doi.org/10.1097/BOR.0000000000000152

47. Husted JA, Thavaneswaran A, Chandran V, Gladman DD (2013) Incremental effects of comorbidity on quality of life in patients with psoriatic arthritis. J Rheumatol 40:1349-1356. https://doi. org/10.3899/jrheum. 121500

48. Mody GM (2017) Rheumatology in Africa-challenges and opportunities. Arthritis Res Ther 19:49. https://doi.org/10.1186/s1307 5-017-1259-3

49. Oyoo O, Moots RJ, Ganda B (2012) Stepping into the state of rheumatology in East Africa. Rheumatology (Oxford) 51:13451346. https://doi.org/10.1093/rheumatology/ker411

50. Njelesani E, Jawad ASM (2017) Global news: building a rheumatology team for East Africa. Rheumatology (Oxford) 56:e50. https ://doi.org/10.1093/rheumatology/kex409

51. Genga EK, Moots RJ, Oyoo OG, Otieno FO (2017) Building a rheumatology team for East Africa: a call for action! Rheumatology (Oxford) 56:1441-1442. https://doi.org/10.1093/rheumatolo gy/kew432

52. Watad A, Al-Saleh J, Lidar M, Amital H, Shoenfeld Y (2017) Rheumatology in the Middle East in 2017: clinical challenges and research. Arthritis Res Ther 19:149. https://doi.org/10.1186/ s13075-017-1359-0

53. Barhamain AS, Magliah RF, Shaheen MH, Munassar SF, Falemban AM, Alshareef MM, Almoallim HM (2017) The journey of rheumatoid arthritis patients: a review of reported lag times from the onset of symptoms. Open Access Rheumatol 9:139-150. https ://doi.org/10.2147/OARRR.S138830

54. Haroon M, Gallagher P, FitzGerald O (2015) Diagnostic delay of more than 6 months contributes to poor radiographic and functional outcome in psoriatic arthritis. Ann Rheum Dis 74:10451050. https://doi.org/10.1136/annrheumdis-2013-204858

55. Betteridge N, Boehncke WH, Bundy C, Gossec L, Gratacós J, Augustin M (2016) Promoting patient-centred care in psoriatic arthritis: a multidisciplinary European perspective on improving the patient experience. J Eur Acad Dermatol Venereol 30:576585. https://doi.org/10.1111/jdv.13306

56. Al Marzooqi AM, Al Saleh J (2016) AB0983 What is the fastest route for patients with inflammatory arthritis to early arthritis clinic? Ann Rheum Dis 75(Suppl 2):1237

57. Hussain W, Noorwali A, Janoudi N, Baamer M, Kebbi L, Mansafi H, Ibrahim A, Gohary S, Minguet J, Almoallim H (2016) From symptoms to diagnosis: an observational study of the journey of rheumatoid arthritis patients in Saudi Arabia. Oman Med J 31:29-34. https://doi.org/10.5001/omj.2016.06

Publisher's Note Springer Nature remains neutral with regard to jurisdictional claims in published maps and institutional affiliations. 